Original Article

\title{
PERCEPTIONS OF HEALTH CARE CONSUMERS, DELIVERERS AND NURSE EDUCATORS ON NURSING PRACTICE
}

\author{
Maxie Andrade', Anice George ${ }^{2} \&$ Erna Judith Roach ${ }^{3}$ \\ ${ }^{1} M$ axie Andrade, Asst. Professor, M anipal College of Nursing, Manipal \\ ${ }^{2}$ Anice George, Dean, Manipal College of Nursing, M anipal. Director, Nursing Education, Manipal University, Manipal. \\ ${ }^{3}$ Erna Judith Roach, Associate Dean \& HOD, Child Health Nursing, Manipal College of Nursing, \\ Manipal University, Manipal. \\ Correspondence: \\ Maxie Andrade \\ Asst. Professor, Manipal College of Nursing, Manipal University, Manipal \\ E-mail : amaxie@ hotmail.com
}

\begin{abstract}
:
Health is a fundamental human right and nurses are considered as the indispensible members of the health team. Nursing education is growing on one side and need for qualified nurses is on the rise owing to growing disease burden. Today nursing practice is within the perview of quality control. Technology oriented nursing of today welcomes nurses with clinical and and technical competency. Knowing the perspectives of consumers and providers in India is very essential at this stage of an attempt of globalizing nursing. In this survey an attempt was made to realize the current perceptions of doctors, nurses, nurse educators and in-patientson nursing practice. The perceptions of consumers significantly varied from other health health team memebrs and this calls the nursing community to unite to raise to the status and standard of nursing.
\end{abstract}

Keywords : Health care providers, consumers, nursing practice

\section{Introduction:}

Nursing education, research and administration have no focus without nursing practice. Through clinical practice, we link the consumers and providers of health care. It is believed that when clients' sense that health care providers are interested in them as 'people', clients will be more willing to follow recommendations and therapeutic plans. Thus the provider consumer relationship is of prime importance.

Studies of consumer perceptions are important because health care is now placing greater emphasis on client satisfaction. Nursing professionals may believe, nursing today is advanced in the spheres of practice, research,

\begin{tabular}{|c|}
\hline Access this article online \\
\hline Quick Response Code \\
\hline \\
\hline
\end{tabular}
e d u c a tion a nd administration. Nursing has moved from a traditional approach with no sound training, to the latest theory based concepts and evidence based practice. Nursing image has changed from the handmaiden's role to the current 'Advanced Nurse Practitioner' role. Is this a one sided perception or is this what health team members also perceive about nursing practice? In order to identify similarities, dissimilarities and misconceptions between health care consumers, deliverers and nurse educators on nursing practice, this study was undertaken.

Objectives: of the study were to:

1. describe the perception of health care consumers, deliverers and nurse educators on nursing practice

2. compare the perceptions of health care consumers, deliverers and nurse educators on nursing practice

Review of literature: Studies related to perceptions on nursing practice per se are not available but there are a number of studies which discuss various elements of nursing practice.A few of them are described here.

The core of nursing is care and caring in nursing has been studied from a variety of philosophical and ethical perspectives since the time of Florence Nightingale. A 
number of nursing scholars have developed theories on caring because of its importance not only to practice of nursing but also to the existence of mankind. Caring is a cherished value in nursing and caring encompasses knowing, doing, enabling, being with and maintaining belief as described by Swanson. ${ }^{1}$

A study was conducted to evaluate the perception of nurses, nursing profession and nursing image among a total of 831 non nursing students, professionals and other nonnursing individuals. Content analysis of the responses revealed that the majority of individuals who participated in the study believed, nursing is most closely associated with the concept of caring. The meaning and practice of nurse caring was defined very differently by respondents. ${ }^{2}$

Caring skills in nursing are unique and depictive of the art of nursing. It is not always the successful performance of a procedure that gives patients the impression a nurse is skilled, but often the caring practices that a nurse shows while performing the technical task. In a study with the purpose to explore patients' perceptions of nurses' skill in a progressive care unit $(n=32)$, revealed that patients' perception of a nurse's skill focused more heavily on the interpersonal skills of the nurse than on technical skills. ${ }^{3}$

Patient satisfaction with nursing care is an indicator of quality care. A study to discover patients' perceptions of the nursing care they receive in a hospital setting using the Grounded theory method among eight medical-surgical patients, recently discharged from an academic medical centre in the south-eastern United States of America, identified four categories of patient perceptions of their nursing care namely, seeing the individual patient, explaining, responding and watching over. ${ }^{4}$

A study on patient satisfaction with nursing care, nursing behavior and environmental factors using both questionnaire and interview techniques for data collection, revealed high mean percentage satisfaction scores in the areas of nursing process (91.38\%), communication $(83.35 \%)$, honesty $(96.83 \%)$, comfort $(93.67 \%)$, rest and sleep (91.75\%) and cleanliness (86.83\%). ${ }^{5}$
Methods and Procedures: The conceptual framework of this study was based on Imogene King's Theory of dynamic interacting systems. Study adopted a survey approach with a descriptive comparative design and was conducted at a teaching Hospital and Schools/Colleges of Nursing of Udupi District. Thirty samples each in three groups namely inpatients (health care consumers), physician/surgeons (health care deliverers), nurses(health care deliverers) were selected through simple random sampling at teaching Hospital and thirty samples for the nurse educators group were selected among Schools and Colleges of Nursing of Udupi District through stratified random(proportionate) sampling. The study was delimited to adult health care consumers as well as health care deliverers rendering care to adult in- patients

Tools were developed by the researcher, were validated by five experts and were translated to Kannada. Data were collected in the month of March 2010, after obtaining administrative permission and participant's informed consent with the pretested tools namely Tool 1: Demographic Proforma (Health care consumers); Tool 2: Demographic Proforma (Health care deliverers - nurses), Tool 3: Demographic Proforma (Health care deliverers physicians/surgeons); Tool 4: Demographic Proforma (Nurse educators); Tool 5: Perceptions on nursing practice and Tool 6: Focus group discussion question plan. Test retest reliability for tool 5 was 0.72 (English) and 0.73 (Kannada). Tool 5 had ten items related to nursing practice. Each correct response was given a score of one.

Study was conducted in two phases. In Phase I, data were collected through tools 1-5 and in phase II, focus group discussions with each group were planned. Pilot study with twelve samples revealed that, data were analyzable but focus group discussion with the groups namely consumers, physicians/surgeons and the final session with all four group's selected participants were not feasible, in terms of organizing the group. Both descriptive and inferential statistics were used to analyze data using PASW (Predictive Analytic Soft Ware) statistic version 18.

Results: Table 1 describes the sample characteristics and 
Fig 1. describes the perception scores. The mean perception scores were as follows: Health care consumers: 3.97(SD 1.33); nurses: 6.40 (SD 1.49); Physicians and surgeons: 6.40 (SD 1.33) and nurse educators: 6.07 (SD 1.51). Study revealed significant differences $\left(x^{2}=41.556\right.$; $p \varangle 0.001$ ) in perception scores between groups on nursing practice. Mann Whitney $U$ test revealed significant differences between consumers and nurses ( $Z=5.128$, $P<0.0125)$ consumers and physicians $(Z=5.563, p<0.0125)$; consumers and teachers $(Z=4.861, P \varangle 0.0125)$. Itemwise perceptionscoresare presented in table 2 .

The self report data and the focus group discussions of the study brought forward a few issues related to nursing practice, which call for actions at institutional and individual level. They are:

I Non nursing activities such as attending telephone call, indenting equipments, linen, supplies and maintenance of stock, checking minor and major items, transporting patients, inspecting electricity, plumbing, housekeeping job etc., consume more than $50 \%$ of the nurses' time and workload. Most of the nursing time goes for documentation which is non patient care.

I Poor nurse patient ratio, lack of equipments and supplies, educated and demanding patients, quality orientation, super-specialization in medicine and surgery, expectations of timely effective care by medical fraternity, increasing bio-medical equipments in the unit, increasing health care team members in the unit, make nursing more challenging and risky in the current practice.

I Nurses lack skills in problem solving, communication techniques and ability to convince the management on needs or resources of the nursing unit. Lack of willingness and uniformity in application of nursing process is a sign of non scientific approach in nursing practice

I Profit oriented health care organizations, less recognition of nurses and nursing's contribution, less budgetary allocation for nursing department, less pay of nurses, less fee of nursing services, hindrance in hiring qualified nursing manpower, recruitment of non qualified nursing personnel and assigning designations as nurses, non-involvement of nurses in planning policies and procedures depicts poor management of nursing manpower.

I Community and hospital are not linked. Most of the nursing care is task oriented, concentrated on physical needs and problems of clients.

I Too many consultants and allied professionals handle one patient and nurses are not authorized to communicate diagnosis and treatment related information to patient and relatives though patients expect information from nurses.

I Care seekers do not make an attempt to identify whether the caring nurse is a licensed or unlicensed nurse. Only licensed nurses should practice and current licensure is for life long. Nurses need to keep abreast with scientific advances and license should be renewed at least once in five years.

I Nursing studies lack methodological orientation (RCT) and moreover the results of the studies are not communicated to practicing nurses nor implemented. Health team members thus are unaware of nursing's contribution in health care.

\section{Discussion :}

The findings and issues brought out in this study support the studies reviewed and have relevance to nursing practice.The current study findings support astudy on consumer perceptions of nursing and nurses in general practice, held in Australia, in which the researcher found lack of awareness and understanding on the scope of nursing in general practice. Nursing community all over the globe needs to bring awareness among the public about themselves, their roles and functions. Nurses should start projecting a positive image through their practice wherever they work.

One of the physicians expressed, "Apart from caring for the patient and carrying out the doctors orders nurses can help the doctor by co-ordinating his/her activities, answering patients' queries whenever within their capacity. However 
I do not encourage the nurses to discuss the disease/prognosis/surgical procedure/outcome with the patient as it may be different from the doctor's view and can cause confusion." This view supports the inference of a study on nurses' and physicians' expectations and perceptions of staff nurse role performance as influenced by status consistency, wherein the researcher found that the staff nurses and physicians significantly differed with regard to perceptions of the independent functions concerning assessment, judgment and carrying out the current independent role being advocated for the staff nurse.

Another study compared perceptions of 163 nurses and physicians of the current and idealstatus of the decisionmaking authority of professional nurses health and patient care which revealed the premise thatin spite of expanded nursing roles emphasizing nursing authority, there are disagreementsbetween nurses' and physicians' perceptions of the current and ideal authority of nurses aswell as areas of dissatisfaction within each professional group.

The current study reveals the perception of health care consumers, deliverers and nurse educators on nursing practice identifies that there are significant differences in their perceptions. Though nurses are considered prime people in health care delivery system by all groups, few nurses feel they are not respected equally as any other health care professional. Consumers as well as physicians/surgeons expect from nurses' motherly qualities, knowledge and skill in practice but nurses feel consumers and physicians expect too much from nurses who are overloaded, undertrained, underpaid and

Table 1: Frequency and percentage distribution of sample

\begin{tabular}{|c|c|c|c|c|c|c|c|c|c|}
\hline \multirow{3}{*}{\multicolumn{2}{|c|}{ Variable }} & \multirow{2}{*}{\multicolumn{2}{|c|}{$\begin{array}{l}\text { Health care } \\
\text { consumers }\end{array}$}} & \multicolumn{4}{|c|}{ Health care deliverers } & \multirow{2}{*}{\multicolumn{2}{|c|}{$\begin{array}{c}\text { Nurse } \\
\text { Educators }\end{array}$}} \\
\hline & & & & \multicolumn{2}{|c|}{ Nurses } & \multicolumn{2}{|c|}{$\begin{array}{c}\text { Physicians/ } \\
\text { Surgeons }\end{array}$} & & \\
\hline & & f & $\%$ & f & $\%$ & f & $\%$ & f & $\%$ \\
\hline \multirow[t]{2}{*}{ Sex: } & Male & 15 & 50.00 & 01 & 3.33 & 18 & 60.00 & 0 & 6.66 \\
\hline & Female & 15 & 50.00 & 29 & 96.67 & 12 & 40.00 & 28 & 93.34 \\
\hline Age in years: & $\leq 30$ & 10 & 33.33 & 06 & 20.00 & 10 & 33.34 & 19 & 63.33 \\
\hline$>30-40$ & & 07 & 23.33 & 07 & 23.33 & 11 & 36.66 & 10 & 33.33 \\
\hline$>40-50$ & & 06 & 20.00 & 13 & 43.33 & 08 & 26.66 & 01 & 3.34 \\
\hline$>50$ & & 07 & 33.34 & 04 & 13.34 & 01 & 3.34 & 00 & 0.00 \\
\hline \multirow[t]{2}{*}{ Religion: } & Hindu & 27 & 90.00 & 18 & 60.00 & 27 & 90.00 & 13 & 43.33 \\
\hline & Christian & 03 & 10.00 & 12 & 40.00 & 03 & 10.00 & 17 & 56.67 \\
\hline \multirow[t]{2}{*}{ Marital status: } & Married & 24 & 80.00 & 25 & 83.33 & 21 & 70.00 & 13 & 43.33 \\
\hline & Single & 06 & 20.00 & 05 & 16.67 & 09 & 30.00 & 17 & 56.67 \\
\hline \multirow[t]{2}{*}{ No. of children: } & None & 09 & 30.00 & 09 & 30.00 & 16 & 53.33 & 21 & 70.00 \\
\hline & $\leq 2$ & 14 & 46.66 & 20 & 66.66 & 14 & 46.67 & 09 & 30.00 \\
\hline$>2$ & & 07 & 23.34 & 01 & 3.34 & 00 & 0.00 & 00 & 0.00 \\
\hline \multirow[t]{2}{*}{ Education: } & $\leq P \cup C$ & 16 & 53.33 & 00 & 0.00 & 00 & 0.00 & 00 & 0.00 \\
\hline & Diploma & 01 & 3.34 & 23 & 76.66 & 00 & 0.00 & 00 & 0.00 \\
\hline \multicolumn{2}{|c|}{ Graduation } & 10 & 33.33 & 07 & 23.34 & 03 & 10.00 & 21 & 70.00 \\
\hline \multicolumn{2}{|c|}{ Post graduation } & 03 & 10.00 & 00 & 0.00 & 27 & 90.00 & 09 & 30.00 \\
\hline \multirow[t]{2}{*}{ Clinical experience } & Nil & & /A & 00 & 0.00 & 00 & 0.00 & 17 & 56.66 \\
\hline & $\leq 2 \mathrm{yrs}$ & & /A & 05 & 16.66 & 05 & 16.67 & 07 & 23.34 \\
\hline \multirow[t]{2}{*}{ (India) } & $>2-5$ yrs & & /A & 01 & 3.34 & 05 & 16.67 & 01 & 3.33 \\
\hline & $>5 y r s$ & & /A & 24 & 80.00 & 20 & 66.66 & 05 & 16.67 \\
\hline \multirow{2}{*}{$\begin{array}{l}\text { Clinical experience } \\
\text { (Outside India) }\end{array}$} & Nil & & /A & 29 & 96.66 & 23 & 76.66 & 30 & 100.00 \\
\hline & $\leq 2 \mathrm{yrs}$ & & /A & 01 & 3.34 & 07 & 23.34 & 00 & 0.00 \\
\hline \multirow{3}{*}{$\begin{array}{l}\text { Teaching } \\
\text { experience: } \\
>2 \text { yrs }\end{array}$} & Nil & \multicolumn{2}{|c|}{ N/A } & \multicolumn{2}{|c|}{ N/A } & 00 & 0.00 & 00 & 0.00 \\
\hline & $\leq 2 \mathrm{yrs}$ & \multirow{2}{*}{\multicolumn{2}{|c|}{$\begin{array}{l}\text { N/A } \\
N / A\end{array}$}} & \multicolumn{2}{|c|}{ N/A } & 03 & 10.00 & 14 & 46.66 \\
\hline & & & & \multicolumn{2}{|c|}{$\mathrm{N} / \mathrm{A}$} & 27 & 9 & 16 & 53.34 \\
\hline
\end{tabular}


moreover not treated as per their qualification and efficiency. The findings from the self report data and focus group disussions call for united actions from nurses of education and service sector to uplift the public image of nursing at institutional and individual levels.

Conclusion: Nurses once thought of as assistants in the health care team, are striving to uplift their image through professionalization of nursing today. Government of India has recognised the role of nurses since independence and has regarded them in the frontline as essential health care providers even today. Nursing services are made accessible and affordable through placement of a trained ANM at the peripheral centres, six decades ago and these ANM stried to liason nursing and health care. However, nursing education has grown far beyond the ANM programme today, and the nursing administration is in the hands of quaified well trained nursing professionals. This study calls for the united efforts and actions at national, institutional and individual level by nurses of all cadres to address the misperceptions and portray the nobleness of the profession in nursing practice.

Table 2: Percentage distribution of perceptions on nursing practice

\begin{tabular}{|c|c|c|c|c|}
\hline \multirow[b]{2}{*}{ Variable } & \multirow[b]{2}{*}{$\begin{array}{l}\text { Health care } \\
\text { consumers \% }\end{array}$} & \multirow[b]{2}{*}{$\begin{array}{c}\text { Nurses } \\
\%\end{array}$} & \multicolumn{2}{|c|}{$N=(30+30+30+30) 120$} \\
\hline & & & $\begin{array}{l}\text { Physicians/ } \\
\text { Surgeons \% }\end{array}$ & $\begin{array}{c}\text { Nurse } \\
\text { Educators \% }\end{array}$ \\
\hline Awareness of ANA standards & 13.33 & 80.00 & 20.00 & 66.66 \\
\hline Nursing proceduresare the & & & & \\
\hline Nursing standards & 80.00 & 16.66 & 63.33 & 6.66 \\
\hline Scope of Nursing practice@ & 46.66 & 66.66 & 76.66 & 63.33 \\
\hline $\begin{array}{l}\text { Obtaining consent for surgery } \\
\text { is nurses responsibility }\end{array}$ & 13.33 & 3.33 & 0.00 & 80.00 \\
\hline $\begin{array}{l}\text { Nursescan initiation of life saving } \\
\text { measures }\end{array}$ & 40.00 & 80.00 & 86.66 & 80.00 \\
\hline Nurses can prescribe medicines as & 5000 & 6333 & 8333 & 8000 \\
\hline $\begin{array}{l}\text { nurses can treat minor ailments } \\
\text { nursing practice is compatibility }\end{array}$ & 60.00 & $\begin{array}{l}0.35 \\
76.66\end{array}$ & $\begin{array}{l}03.35 \\
76.66\end{array}$ & 80.00 \\
\hline with scientific advances & 53.33 & 53.33 & 70.00 & 66.66 \\
\hline $\begin{array}{l}\text { Nurses demonstrate responsibility } \\
\text { and accountability }\end{array}$ & 66.66 & 83.33 & 100.00 & 96.66 \\
\hline Functions of nurses\# & 56.66 & 73.33 & 86.66 & 90.00 . \\
\hline $\begin{array}{l}\text { Nursing practice is guided by the } \\
\text { code of ethics }\end{array}$ & 23.33 & 63.33 & 86.66 & 80.00 \\
\hline $\begin{array}{l}\text { Nursing diagnosis is derived } \\
\text { from the medical diagnosis }\end{array}$ & 36.66 & 56.66 & 76.66 & 50.00 \\
\hline
\end{tabular}

\$ Bed making, carrying out doctors orders, medication administration, attending rounds, transporting patientsetc.

@ Promoting health and wellness, preventingillness, restoring health, care of dying

\# Orientation to unit, explanation of procedures, communication of progress/regress status 


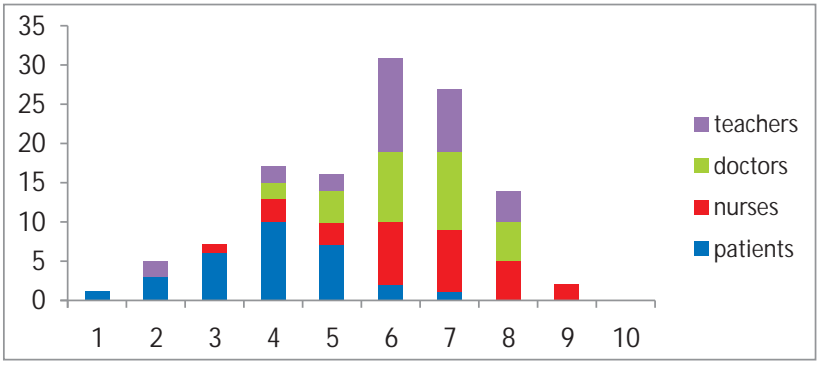

Perception scores on nursing practice

Fig 1: Bar diagram on perception scores on nursing

\section{References:}

1. Swanson KM. Empirircal development of a middle range theory of caring. Nursing Research. 1991; 40 (3): 161-166.

2. Huffstutler SY, Stevenson SS, M ullins I L, Hackett D A, Lambert A W. The public's image of nursing as described by baccalaureate prenursing students. Journal of professional nursing. 1998; 14(1): 7-13.

3. Wysong P R, Driver E. Patients' perceptions of nurses' skills. Critical care nurse. 2009; 29: 24-37.

4. Schmidt $L A$. Patients' perceptions of nursing care in the hospital setting. Journal of advanced nursing 2003, 44(4): 393-399.

5. George B K. A study on patient satisfaction with the nursing care received, nurses behavior and environmental factors among patients admitted in general medical surgical wards of a selected hospital of Karnataka state. 2004: M AHE

6. Cheek J, Price K, Dawson A, M ott K, Beiby J, Wilkinson D. Consumer perceptions of nursing and nurses in general practice report. Adelaide: Centre for research into nursing and health care; 2002

7. Chaska N L. The nursing profession turning points. St. Louis: The C.V. M osby Company; 1990. 